\title{
El clero secular de Nueva España y la búsqueda de grados de bachiller
}

\author{
Rodolfo Aguirre \\ Universidad Nacional Autónoma de México \\ aguirre_rodolfo@hotmail.com
}

\begin{abstract}
Resumen
Este artículo compara los argumentos de un claustro universitario acerca de que no es necesario que el clero obtenga grados académicos, con la petición de un obispo para convertir su seminario en universidad. Aunque el claustro negó que los clérigos necesitaran grados, en realidad desde el siglo XVI la Iglesia tuvo interés en consolidar la fundación universitaria. Los arzobispos de México vieron en la universidad un espacio para la formación del clero, la cual les era exigida para la ordenación sacerdotal. Si bien no había ley que exigiera al clérigo medio un título universitario, en la práctica la mayor parte de la clerecía lo tuvo. Negar la relación entre la carrera eclesiástica y los grados sólo se entiende como una estrategia para evitar una segunda universidad en Nueva España que trastocara el monopolio de los grados detentado por la Universidad de México.
\end{abstract}

Palabras clave: clero secular, Nueva España, grados universitarios, seminario conciliar, formación clerical.

\begin{abstract}
This work compares the arguments of a university cloister on the no necessity of the clergy to receive university degrees, with the request of a bishop to turn its seminary into university. Although the cloister denied that the clergymen needed degrees, in fact from century XVI the Church had interest in consolidating the university foundation. The archbishops of Mexico saw in the university a space for the formation of the clergy, same who was to them demanded for the sacerdotal arrangement. Although there was no law that demanded to the average clergyman a university title, actually most of it had it to the clergy. To deny the relation between the ecclesiastical race and the degrees is only understood like a strategy to avoid one second university in
\end{abstract}




\section{FRONTERAS}

de la fistoria

Vol.13-1 / 2008

the New Spain that would finish with the monopoly of the degrees held by the one of Mexico.

Key words: secular clergy, New Spain, university degrees, council seminary, clerical formation.

\section{La Real Universidad de México y la Iglesia: una relación compleja}

Las conexiones o interrelaciones que se establecían entre las instituciones y corporaciones en Nueva España son un aspecto complejo debido a la diversidad de factores que podían entrar en juego. Si bien la novohispana era una sociedad organizada en corporaciones de todo tipo, hay que considerar que éstas no fueron entidades cerradas que impidieran a sus miembros integrarse a otras.

Desde esta óptica, las investigaciones sobre la Real Universidad de México y sus graduados me han llevado a considerar que la historia de esta corporación no puede entenderse pasando por alto la evolución del clero secular y sus instituciones. Para las autoridades virreinales, la universidad era casi una comunidad eclesiástica. Esta afirmación resulta, por demás, provocativa, puesto que desde que se fundó, esa corporación se consideró un estudio general donde podían cursar tanto laicos como clérigos. No obstante, en el transcurso del siglo XVII la universidad mexicana cayó en la esfera de acción de la poderosa Iglesia colonial. Aunque nunca llegó a depender directamente del arzobispo de México, su estructura y sus órganos de gobierno fueron ocupados por clérigos que muchas veces eran dependientes del prelado. Las decisiones importantes sobre su devenir se dictaban en el claustro universitario, dominado por doctores con muchas ligas con el alto clero. En tanto, el espacio que los laicos ocuparon ahí fue mucho menor, especialmente en el siglo XVIII.

Tales procesos se vieron reflejados en el gran crecimiento que tuvieron las facultades de Cánones y Teología, en contraste con las de Leyes y Medicina, que se estancaron desde principios del siglo XVIII y hasta las guerras de Independencia (Aguirre, El mérito). La influencia ejercida por el clero en la universidad mexicana fue permitida y bien vista por los monarcas españoles, pues una iglesia fuerte y leal al imperio, que controlara la formación de letrados e intelectuales en la rica colonia novohispana, era muy conveniente.

Pero las relaciones entre la Real Universidad de México y las instituciones eclesiásticas no se agotaban en su cúpula. Pensemos, por ejemplo, en la presencia de curas y canónigos en las cátedras y en la Rectoría de la Universidad, en el papel 
de la academia en las carreras eclesiásticas, en el significado de la universidad en la dinámica de las instituciones eclesiásticas, o bien, en la formación de clérigos. Este último aspecto ayuda mucho a entender las ligas de ambas entidades en cuanto al interés común de formar y promover los cuadros de clérigos que se necesitaban para la renovación de las instituciones eclesiásticas.

En el siglo XVIII la búsqueda de grados por parte de la clerecía novohispana llegó a su apogeo. Es probable que las instituciones eclesiásticas llegaran en ese siglo a su mayor crecimiento, provocando una demanda de títulos universitarios no vista hasta entonces.

El objetivo central de las siguientes páginas es, pues, discutir la estrecha relación que guardaron en Nueva España las trayectorias de los clérigos y la búsqueda de grados de bachiller. Ello, por más que un claustro universitario de 1753 quisiera precisamente negar esa relación histórica, buscando impedir la creación de una segunda universidad en Nueva España que pudiera competirle, e igualmente defendiendo la expedición de grados académicos que sólo la de México había tenido hasta entonces.

\section{Los grados y el sacerdocio, según un claustro universitario de 1753}

El 3 de marzo de 1753, el claustro pleno de la Universidad de México envió un parecer por escrito, solicitado por el virrey, sobre la pretensión del obispo de Oaxaca de fundar otra universidad, tomando como base el seminario conciliar de esa jurisdicción (AGN, U 55, ff. 51-55). Aunque no era novedad que la universidad se opusiera a la apertura de otro estudio general, esta vez los contraargumentos que presentó en su escrito giraron en torno, precisamente, a la relación de los grados universitarios con la formación eclesiástica. De entrada, la universidad declaró:

[...] no poderse hacer dicha fundación en la forma que se propone, no ser necesaria ni conveniente y ceder totalmente en perjuicio así de esta universidad como de los estudios de este reino. (AGN, $U$ 55, f. 51)

Cuando el obispo afirmó que "los fondos del seminario son competentes para la manutención de los colegiales" y que se podían costear las cátedras de

El claustro pleno de era el máximo órgano de gobierno de la universidad pues ahí se discutían los problemas más importantes y asuntos que tenían que ver con la marcha en general de la corporación, como en este caso la apertura de una nueva universidad en el centro de la Nueva España. 


\section{FRONTERAS}

de la fistoria

Vol.13-1 / 2008

Moral, Escritura, Teología Escolástica, Filosofía, Gramática, Prima de Cánones, Leyes y Medicina, el claustro universitario replicó:

[...] sólo con esta representación se ve manifiesto oponerse a la decisión del Santo Concilio de Trento en la sesión 23, capítulo 18 [...] manda que se les enseñe gramática, canto, cómputo eclesiástico, sagrada escritura, historia eclesiástica, homilias de santos padres, moral, ritos y ceremonias eclesiásticas ${ }^{[2]}$. Ignora esta real universidad como faltando en dicho colegio maestros que les instruyan a los colegiales en lo que expresamente manda el santo concilio, quiera vuestro reverendo obispo, con las rentas del mismo colegio, fundar cátedras de facultades muy extrañas y no correspondientes al fin que intenta el santo concilio; dice que se les instruyan en otros buenos artes, esto se entiende, no buenas absolutamente sino respectivas y conducentes al fin y de ningún modo lo es las cátedras de las otras facultades, pues la que más conducencia podía tener es la de sagrados cánones, y esta como en lo regular se aplique no para la administración de las almas sino para los negocios forenses, que les es indecente a los clérigos [...] razón porque les esta prohibido a los de orden sacro el ejercer el oficio de abogados [...]. (AGN, $U 55$, f. 51)

El hecho de que el claustro hablara de "facultades extrañas" a la formación clerical no puede entenderse sino en el único contexto de convencer al virrey de negar la solicitud del obispo de Oaxaca, pues al revisar las relaciones de méritos de la clerecía novohispana es raro aquel que no estudió por lo menos una de las asignaturas impartidas en la universidad (Aguirre, El mérito 279392). Si vemos al conjunto de doctores canonistas del siglo XVIII, es fácil constatar que la mayoría ingresó al clero (Aguirre, El perfil 51-84). ¿Y qué decir de los bachilleres canonistas, muchos de ellos clérigos, jueces eclesiásticos y abogados con dispensa papal para poder ejercer?

Regresando al parecer de la Universidad, el claustro insistió en que la enseñanza de cánones en un seminario tridentino no tenía cabida: “[...] ni aun la cátedra de cánones, por el mal uso que de ello se tiene, se debe permitir en dicho colegio [...]" (AGN, U 55, f. 51v.); es decir, que no se les diera a los clérigos ocasión para ocuparse en algo contrario a su ocupación religiosa de curar almas.

2 Si le faltaba alguna de esas asignaturas, apenas merecía el nombre de sacerdote, como dice el capítulo Queipsis Dist. 38. 
Otra razón esgrimida por el obispo a favor de la fundación era la gran distancia entre México y Oaxaca, pues el viaje de los estudiantes a la capital para poder conseguir sus grados era costoso y riesgoso. Ante ello, el claustro contestó que los seminaristas debían prepararse para salvar almas, no para conseguir grados: "[...] el santo concilio no manda que se gradúen, sino que estudien y sepan lo que ya esta dicho, pues para el bien de las almas lo que conduce es la ciencia y no los grados".

El claustro proponía, en cambio, que el obispo fundara más colegios seminarios y no otra universidad. A continuación, explicaba cómo se había salvado el afán de los estudiantes de las regiones del interior novohispano de obtener los grados:

[...] sin embargo, teniendo consideración a la distancia de las tierras y pobreza de sus habitadores para que los que estudian fuera de la universidad no se imposibilitasen de poder conseguir los grados, se admiten para ellos, por estatuto expreso, los colegiales de los colegios seminarios agregados a catedrales, y para los otros que no lo son ha informado a su favor la universidad siempre que se ha ofrecido el que ocurran al excelentísimo señor virrey para conseguir el que se les admita, y de hecho casi no hay ciudad en el reino donde haya estudios de gramática, filosofía y teología donde no se admitan en esta universidad los cursos para que se gradúen en ella. (AGN, $U$ 55, f. 52)

La distancia geográfica - proseguía el claustro- no era tanta como decía el obispo, pues era mayor entre México y las ciudades de Guadalajara, Durango o Zacatecas, y entonces con más razón habría que fundar universidades ahí. Agregaba que una universidad en Oaxaca estaría aislada y con pocos asistentes, pues incluso faltaban alumnos en el colegio de la Compañía de Jesús. Además, según la Universidad, un seminario tridentino dependía del obispo o el cabildo en sede vacante, y una universidad, del rey mismo, por lo que eran incompatibles. Otro problema que veía el claustro, inteligentemente, era la capacidad de un obispo para gobernar una universidad:

[...] siendo tan grande la autoridad y mando que en las partes de las Indias tienen [los obispos] como considera el experimentado político y maestro de ellas el señor Solórzano libro 4, capítulo 14 pendiera de su arbitrio la provisión de las cátedras y colación de grados, dando uno y otro a los menos dignos por ser sus más afectos, haciendo que con los grados conferidos sin la suficiencia necesaria, y sin los cursos por habérselos dispensado, se antepusiesen a los dignos, siguiendo su pasión y no la razón [...]. (AGN, $U$ 55, f. 52v.) 


\section{FRONTERAS}

Parece que al claustro se le olvidaron tantas dispensas de grados y el sistema clientelista de dar las cátedras en la misma universidad. Para apoyar los inconvenientes de una universidad bajo el gobierno diocesano, el claustro hizo alusión a las disputas que provocaban las oposiciones a canonjías, curatos y cátedras, las tres prebendas básicas en una carrera eclesiástica. Luego de todo ello, el claustro insistió en que los seminaristas necesitaban ciencia para el desempeño de sus labores, no los grados, que eran de utilidad particular solamente:

[...] con la suficiencia, pueden los ministros hacer en la iglesia todo lo que pueden hacer con los grados y esta suficiencia no ha de ser indiferente de todas las facultades, sino sólo aquellas que fueren más conducentes al fin de las almas y para que se crían los ministros [...] y no podrá negar el señor obispo, antes lo confiesa en la representación que hizo a su majestad, que en dicho colegio de Oaxaca se lee gramática, artes y teología, y que lo mismo se enseña en el colegio de la compañía de Jesús de dicha ciudad, y por consiguiente, que tiene maestros que enseñen las ciencias conducentes a la utilidad pública de la iglesia y toda la mira del señor obispo debía ser el que éstas se aprendiesen [...] prescindiendo de la utilidad particular de los grados para lo cual podía tomar la providencia que da la ley 8 título 23 libro I de Indias, de remitir y mantener en los colegios de México hasta recibir el grado de bachiller en la universidad dos colegiales del seminario de Oaxaca, y más cuando para que no se priven de la utilidad particular de los grados se ha dispuesto con consentimiento de la universidad, el admitirse en ella los cursos que ganaren en dicho colegio seminario, y en el de la compañía [...]. (AGN, $U$ 55, ff. 53-53v.)

Para el claustro, el paso de seminario a universidad era también cuestión de números. Alegaba que no constaba si habría suficiente número de estudiantes manteístas, no colegiales, para llenar las aulas de un estudio general. En opinión del claustro, había pocos manteístas o estudiantes laicos, según se veía en los graduados de Oaxaca registrados en la universidad.

Además, se correría el riesgo — continuaba el claustro- de reducir la universidad mexicana a un estudio particular de la diócesis, como seguramente quedaría igual la de Oaxaca; esto impediría que fueran a México los mejores estudiantes de otras tierras, y quedarían sólo los comunes y en menor número. Otra consecuencia de la fundación sería la extinción del colegio jesuita, tan importante por la enseñanza de sus doctrinas.

Al final de su parecer, el claustro opinó que la pobreza de los estudiantes no era una razón para que dejaran de viajar a México a graduarse: 
Y en lo que mira a la pobreza, raro o ninguno deja por este motivo de venir a graduarse, por venir ayudados de los otros que tienen posibilidad, y si algunos se quedan será porque no han hecho más que perder el tiempo sin aprovecharlo [...]. (AGN, $U$ 55, f. 55)

¿Cómo valorar esta serie de argumentos del claustro universitario en 1753, que contradecían por completo la evolución del clero novohispano y los grados? Indudablemente, se trata de un escrito político para evitar la fundación de otra universidad en la Nueva España, para lo cual se argumenta la diferencia de objetivos de formación entre una universidad y un seminario diocesano, separación que en los hechos no se daba, pues para el siglo XVIII la gran mayoría de los clérigos contaba con al menos el grado de bachiller. ¿Cómo se había dado tal relación?

\section{La formación del clero y la universidad}

Es sabido que en la Edad Media los papas fomentaron en mucho la creación y consolidación de las universidades, brindándoles privilegios y dando cargos y prebendas a sus graduados. En España no fue diferente: los graduados de las universidades de Salamanca o Valladolid, por ejemplo, fueron muy favorecidos.

No obstante, en el siglo XVI se presenció el nacimiento de universidades bajo patronazgo del rey, como la de Alcalá, o en América, la de Lima y la de México. El interés de la monarquía española en fundar universidades no fue, por supuesto, accidental. Tal como el papado promovió antes, la formación de teólogos y juristas para la Iglesia, ahora los reyes requerían sobre todo los segundos para el establecimiento y conservación de sus propias instituciones. Así, las universidades de la época moderna, como lo señaló Kagan, se convirtieron en semilleros de funcionarios y clérigos al servicio de la Corona y de la Iglesia.

En este amplio contexto debemos entender el devenir histórico de la Real Universidad de México, aunque en su caso con una variante determinante: en Nueva España, por un lado, ante la falta de otras universidades — pues la de Guadalajara se abrió en 1792-y, por otro, los apuros de la Iglesia secular por carecer de centros de formación propios, el estudio mexicano fue la solución. La monarquía así lo entendió y sólo defendió su patronazgo, dejando al clero que, a la larga, gobernara la universidad.

Por lo que respecta a la formación local de clérigos, desde las primeras juntas eclesiásticas del siglo XVI, donde se reunieron obispos y provinciales de las 


\section{FRONTERAS}

órdenes religiosas, hubo una preocupación de los frailes por formar un clero nativo ${ }^{3}$. Por esos años — década de 1530 , sobre todo—, la atención se centró en si los indios debían o no acceder al sacerdocio. Los franciscanos fueron más lejos al fundar el colegio de Tlatelolco y demostrar la capacidad de los naturales para tales destinos (Gonzalbo 128-148).

No obstante, fue un intento muy temprano y ante todo por razones políticas se impidió la formación de un clero indígena por entonces. Hacia mediados del siglo XVI la realidad mostró que el futuro de la clerecía se hallaba en realidad en la descendencia de los colonizadores (Menegus y Aguirre). Muy pronto se abrieron noviciados de las órdenes religiosas para la formación de los futuros frailes.

En cuanto al clero secular, la formación de sus futuros cuadros fue menos clara en el siglo XVI, pues los primeros obispos carecieron de los recursos, instituciones y hombres suficientes para contrapesar a las omnipresentes órdenes religiosas. La segunda mitad del siglo XVI fue determinante para que la universidad uniera su futuro al de la Iglesia. Como diferentes estudios demostraron ya hace varios años, el alto clero secular de esa época tuvo mucho interés en consolidar una universidad al servicio de la Iglesia, donde un renglón importante era, precisamente, la preparación de los clérigos ${ }^{4}$.

Al carecer de escuelas o seminarios propios para la formación sacerdotal, el clero secular vio en las cátedras universitarias una solución. Aunque en el Concilio de Trento se había ordenado la fundación de por lo menos un colegio seminario en cada diócesis, a cargo y con dotación episcopal, su puesta en práctica quedó relegada ante la pugna que se libraba con el clero regular por el control de las doctrinas de indios. Las condiciones estaban dadas para que el alto clero se interesara por dirigir la universidad para garantizar la formación de los clérigos, no sin enfrentarse a los miembros de la Real Audiencia y el virrey durante algunas décadas, quienes tenían sus propios planes para ella.

Simultáneamente, Felipe II promovió que en la carrera eclesiástica en Indias los grados universitarios tuvieran un peso importante. En la real cédula del patronato de 1574, en la cual se puntualizaba la forma en que la corona ejercería el nombramiento de los cargos eclesiásticos y las prebendas, se declaraba

3 Para una edición moderna sobre las juntas eclesiásticas pueden verse en: Aguirre, Pérez y González.

$4 \quad$ Ver Ramírez y Pavón (56-100); González. 
expresamente que los letrados con grado de teología y cánones fueran preferidos en los nombramientos para dignidades, canonjías y prebendas de las catedrales 5 . Igualmente, para ocupar las canonjías de oficio de las catedrales, se advertía expresamente que debían ser ocupadas por graduados en alguna facultad universitaria.

Las cosas ya no son tan claras cuando la cédula se ocupa de los beneficios simples y curatos; es decir, el grueso de los cargos destinados al clérigo medio. En el documento en cuestión, en ningún momento se hace alusión expresa, como para las prebendas y canonjías, a la posesión de grado o cursos de facultad para poder aspirar a uno de esos beneficios; en realidad, se deja al arbitrio del prelado los criterios de selección, como se infiere de las siguientes líneas:

[...] E de los que así se opusieren y de todos los demás que al prelado pareciere ser competentes personas para el tal oficio o beneficio, habiéndolos examinado e informándose de sus costumbres y suficiencia, elija dos personas de ellos, los que según Dios y su conciencia le parecieren más competentes para el tal oficio y beneficio [...]. (Aguirre, Pérez y González)

Más adelante, la cédula del patronato enunciaba ciertos principios o criterios muy generales para designar a los clérigos, por lo cual estaban sujetos a variadas interpretaciones, como se desprende de la orden de Felipe II a los virreyes y obispos, a la hora de enviar relaciones de clérigos beneméritos a España:

[...] hagan lista de todas las personas eclesiásticas y religiosas y de los hijos y vecinos y de españoles que estudian y quieren ser eclesiásticos, y de la bondad, letras y suficiencia y calidades de cada uno, expresando sus buenas partes y así mismo los defectos que tuvieren [...]. (Aguirre, Pérez y González)

Como es posible advertir, aunque en ningún momento se expresa que los aspirantes a los beneficios eclesiásticos deban tener grados, sí se menciona la posesión de letras y que sean estudiantes. Si revisamos la normativa conciliar vigente en Nueva España desde la segunda mitad del siglo XVI, o sea Trento y los concilios provinciales básicamente, tampoco hallamos mención expresa de los grados como requisito para la ordenación sacerdotal o la ocupación de prebendas o beneficios eclesiásticos (Aguirre, Formación 337-362).

\footnotetext{
5 “[...] Queremos que para las dignidades, canonjías y prebendas de las iglesias catedrales de las Indias, en las presentaciones que hubiéremos de hacer, sean preferidos los letrados a los que no lo fueren [...]" (Aguirre, Pérez y González).
} 


\section{FRONTERAS}

Para el siglo XVII vamos a presenciar la fundación gradual de seminarios de inspiración tridentina que eventualmente cubrirían la demanda de clérigos en Puebla, Oaxaca, Guadalajara y México. No obstante esas fundaciones, todo parece indicar que los clérigos siguieron demandando grados, sobre todo los del valle de México y de la región poblana. Si nos atenemos únicamente a los bachilleres de los seminarios tridentinos de ambas regiones, tenemos lo siguiente: en 1705 se graduaron de bachilleres en artes 15 colegiales de México y 17 de Puebla; en 1717 fueron 34 y 18, respectivamente; en 1721, 22 y 15, y en 1744, 30 y 18. Así, entre 1700 y 1767 el seminario de México graduó hasta 711 de sus alumnos, mientras que su similar de Puebla lo hizo con 740 (Aguirre, Grados 50-52). Por supuesto que no podemos asegurar que todos esos colegiales eran clérigos, pero es muy razonable pensar que lo fueron mayoritariamente.

Ante ese panorama estamos ya en condiciones de preguntarnos: si la normativa eclesiástica no exigía de manera generalizada la posesión de grados de universidad a sus clérigos, salvo para las prebendas y canonjías, ¿por qué los obtenían de todos modos? ¿Acaso la formación que recibían los clérigos en las cátedras de universidad los preparaba también para sus tareas pastorales, no obstante la existencia de colegios y seminarios ex profeso para su formación? Para abordar tal problemática veremos concretamente lo que sucedía en el arzobispado de México hacia la primera mitad del siglo XVIII. Para ello necesitamos puntualizar los requisitos que en la práctica cumplían los clérigos ordenantes y si recibían toda su formación en las cátedras.

\section{La ordenación de clérigos en el arzobispado de México}

En el arzobispado se había consolidado una serie de estructuras y de procedimientos que se ponían en movimiento en cada temporada de órdenes sacerdotales, siguiendo las pautas marcadas en el concilio de Trento. En ellas estaban involucrados personajes y varias instituciones del mundo clerical. La fase más importante consistía en la realización de los sínodos o exámenes de conocimientos. Una vez que el arzobispo aceptaba la solicitud, el aspirante debía superar varias pruebas y revisiones sobre los cuatro aspectos básicos estipulados en los concilios: la preparación, el origen social, la honestidad en el vivir y la posesión de un patrimonio o renta.

Para revisar la ciencia o preparación de los candidatos a órdenes sacras, éstos eran sometidos a diferentes exámenes. El arzobispo Lanciego nombraba a tres examinadores sinodales que revisaban los conocimientos de gramática 
latina, teología moral y lengua mexicana, la más hablada en el arzobispado (AGN, BN 41, exp. 6, ff. 39-39v.). Gracias a que se ha conservado un libro de exámenes de clérigos, que abarca de 1717 a 1727, podemos dar cuenta de la dinámica seguida en estas jornadas (AGN, BN 271, exp. 1). Los examinadores iban anotando al margen de cada registro las calificaciones que cada individuo les merecía: suficiente o no para la orden solicitada, muy bueno o deficiente en lengua, en gramática o moral. Incluso se anotaban algunas recomendaciones: "Estudie más gramática", "Vaya al seminario", "Ejercite más la lengua", por mencionar las más recurrentes. Finalmente, se anotaba si el ordenante era aprobado o reprobado. No es raro hallar que los sinodales enviaran a los aspirantes reprobados a estudiar al seminario. Es el caso de Juan Sainz de Cevallos, de 23 años, quien en 1722 se presentó para lograr las órdenes menores y fue reprobado; la anotación del sinodal fue tajante: "Vaya al seminario y ejercítese en gramática y moral" (AGN, $B N 1271$, exp. 1, f. 72v.). Llama la atención que ningún sinodal haya mencionado los cursos de la universidad. ¿Se habían convertido éstos en mero trámite para la obtención de los grados, más que para la formación sustancial del clérigo?

Buscando profundizar en la formación general de los clérigos y en el papel de los grados, veamos lo que señalan otras fuentes. En las relaciones de méritos de los clérigos es posible tener un panorama que, en primera instancia, nos señala que la clerecía del arzobispado podía formarse en la universidad, en los colegios y en los curatos, al lado de párrocos ya experimentados. En ese sentido, podemos hallar un matiz importante respecto a lo estipulado en Trento y en el tercer concilio mexicano, pues mientras que en éstos se daba mayor peso a los conocimientos más relacionados con la labor pastoral, en la práctica del siglo XVIII podía haber presbíteros y prebendados formados predominantemente en lo académico. Para éstos, la cura de almas no entraba en sus planes necesariamente (Aguirre, El mérito 279-392).

¿Acaso la universidad servía a los clérigos más para su participación en actos académicos en los que podían ejercitarse en la oratoria y en la discusión lógica? En las relaciones de méritos es común que ellos destaquen, más que los cursos, su participación en tales actos que, entre otros fines, los prepararían para sus futuras tareas espirituales. Así, el clérigo pasaba de las oraciones panegíricas y latinas escolares, a las morales y funerarias y a los sermones; de las disputas y oposiciones, a cátedras a los sínodos para curatos vacantes.

Por otro lado, es también evidente que la formación escolástica en latín, filosofía y teología era muy apreciada por la jerarquía eclesiástica, independien- 


\section{FRONTERAS}

temente de la instrucción en administración de sacramentos. De otra manera no se explicaría el hecho de que un mismo individuo pudiera presentar la misma relación de méritos académicos tanto para opositar a una cátedra como para curatos y canonjías. Entendiendo ello es más fácil comprender la presencia de los clérigos en la universidad. En el seminario tridentino de México también se enseñaba latín, filosofía, teología moral y escolástica, y aunque se nombró inicialmente a un maestro de canto, al parecer no hubo continuidad (Chávez 160-162). No hay referencias para esta época a las demás materias señaladas en Trento: cómputo eclesiástico, música y ritos religiosos.

Otro espacio de formación podía ser el de las academias, ya sea aquéllas de los mismos colegios o de la universidad, o las llamadas "particulares". El doctor Miguel de Araujo en su época de estudiante participó en una academia fundada por Juan José de Eguiara y Eguren para pasantes teólogos, quien expresaba en su relación que ahí:

[...] tuvo muchas de las funciones que se acostumbran para instrucción de la juventud, como son oraciones latinas y sermones, hasta llegar a desempeñar la primera y más solemne función del poético anual certamen [...]. ("Provisión”)

Por su parte, el presbítero Antonio Manuel de Figueroa presumía que había fomentado la fundación de una academia de materias morales en la iglesia de la Santísima Trinidad, "a que concurrían diariamente más de treinta sujetos, en los que se experimentó notable aprovechamiento" ("Provisión").

Paralelamente, en el arzobispado de México el colegio de San Pedro y San Pablo y el seminario tridentino desempeñaron un papel central en el siglo XVIII respecto a la formación de los clérigos. El colegio jesuita fue hasta 1767 el que más alumnos graduó de bachiller en artes, el grado más común de los clérigos en Nueva España (Aguirre, El mérito 232). Por supuesto que no todos sus estudiantes ingresaron a la iglesia, pero ahí se formó un buen número, incluyendo a miembros del alto clero.

Por lo que respecta a los seminarios tridentinos, su fundación en Nueva España no fue de ninguna manera tarea fácil, por todos los obstáculos a que tuvieron que hacer frente los prelados, principalmente la falta de rentas. En el siglo XVII se abrieron los más importantes: el de Puebla en 1647, el de Oaxaca en 1681, el de Ciudad Real en 1678, el de Guadalajara en 1696 y el de México en 1697. 
Tales hechos ayudaron, sin lugar a dudas, a lograr cierta independencia del clero secular de los jesuitas, con respecto a su formación ${ }^{6}$. Por ello no es de extrañar que entre 1703 y 1767 los seminarios conciliares hayan absorbido a una tercera parte de los estudiantes (Aguirre, El mérito 228-234). La población estudiantil de los colegios jesuitas se mantuvo más o menos estable, y si creció ya no fue de forma dinámica sino estática, debido no tanto a los progresos de los mismos colegios, sino de la población. El impacto del Seminario de México en el arzobispado puede medirse si comparamos el número de bachilleres que se formaron en sus aulas con los de San Pedro y San Pablo:

\section{Tabla 1}

\section{Bachilleres del Colegio San Pedro y San Pablo y del Seminario Conciliar de México entre 1704 y 1767}

\begin{tabular}{|c|c|c|c|c|c|}
\hline Año & Jesuita & Seminario & Año & Jesuita & Seminario \\
\hline 1704 & 41 & - & 1736 & 51 & 6 \\
\hline 1705 & 36 & 15 & 1737 & 31 & 32 \\
\hline 1706 & 20 & - & 1738 & 38 & 20 \\
\hline 1707 & 7 & 34 & 1739 & 51 & 28 \\
\hline 1708 & 34 & - & 1740 & 26 & 30 \\
\hline 1709 & 28 & 7 & 1741 & 56 & 28 \\
\hline 1710 & 44 & - & 1742 & 59 & 17 \\
\hline 1711 & 22 & 9 & 1743 & 58 & 17 \\
\hline 1712 & 28 & - & 1744 & 43 & 30 \\
\hline 1713 & 22 & 16 & 1745 & 63 & 2 \\
\hline 1714 & 39 & - & 1746 & 54 & 12 \\
\hline 1715 & 35 & 17 & 1747 & 55 & 40 \\
\hline 1716 & 15 & 16 & 1748 & 37 & 25 \\
\hline 1717 & 44 & 17 & 1749 & 49 & 22 \\
\hline 1718 & 78 & 10 & 1750 & 49 & 26 \\
\hline 1719 & 17 & 27 & 1751 & 42 & 33 \\
\hline 1720 & 62 & 21 & 1752 & 60 & 12 \\
\hline 1721 & 36 & 22 & 1753 & 34 & 26 \\
\hline
\end{tabular}

6 Tal hecho lo ha señalado recientemente para el caso de Valladolid (León 193-201). 


\begin{tabular}{|c|c|c|c|c|c|}
\hline Año & Jesuita & Seminario & Año & Jesuita & Seminario \\
\hline 1722 & 42 & 4 & 1754 & 53 & 12 \\
\hline 1723 & 40 & 16 & 1755 & 41 & 26 \\
\hline 1724 & 41 & 32 & 1756 & 42 & 26 \\
\hline 1725 & 52 & 34 & 1757 & 47 & 21 \\
\hline 1726 & 82 & 1 & 1758 & 40 & 19 \\
\hline 1727 & 29 & 18 & 1759 & 49 & 26 \\
\hline 1728 & 45 & 26 & 1760 & 53 & 22 \\
\hline 1729 & 53 & 19 & 1761 & 36 & 14 \\
\hline 1730 & 31 & 8 & 1762 & 37 & 21 \\
\hline 1731 & 49 & 31 & 1763 & 38 & 17 \\
\hline 1732 & 66 & 22 & 1764 & 29 & 28 \\
\hline 1733 & 35 & 16 & 1765 & 32 & 29 \\
\hline 1734 & 29 & 29 & 1766 & 36 & 28 \\
\hline 1735 & 40 & 36 & 1767 & 50 & 27 \\
\hline \multicolumn{7}{|c}{ Total } & $\mathbf{2 . 6 8 1}$ & $\mathbf{1 . 2 2 5}$ \\
\hline
\end{tabular}

Fuente: AGN, $U$, vols. 167-170; 293.

Los graduados de San Pedro y San Pablo representan más del 30\% de todos los bachilleres en artes de la Nueva España, mientras que los del conciliar ascienden a casi el 14\% del mismo universo; es decir, estamos hablando de que entre los dos colegios graduaron al $44 \%$ de los bachilleres en artes entre 1704 y 1767 . Otro matiz importante es el de aquellos clérigos que se formaron en ambos colegios, como fue el caso de Bernardino Pablo López y Escobedo, quien cursó en San Pedro y San Pablo gramática y retórica y de ahí pasó al seminario tridentino a estudiar artes ("Relación").

Respecto a las lenguas indígenas, que no eran un requisito para el grado universitario aunque sí había cátedra de náhuatl y otomí en la universidad, su conocimiento había adquirido gran importancia. Su aprendizaje era un rubro central para muchos clérigos, tomando en cuenta que todavía en 1764 había en el arzobispado 70 curatos donde predominaba el náhuatl; en 27, el otomí; en 5, el mazahua; en 2, el huasteco, e incluso en uno, el tepehua ("Informe"). El cura interino de San Juan de Valle Real: "[...] es mi oficio entenderles las dos lenguas que hablan, como es el chinanteco y zapoteco, y ser ellas mi patrimonio [...]" (AGN, $A M 3$, exp. 35, ff. 204-212v.). Y cómo no iba a serlo, si hay pruebas fehacientes de que un importante porcentaje de clérigos se ordenaban a título de idioma. En 1717 fueron 47 de 114; en 1722, 151 de 261, y en 1727, 113 de un total de 192 (AGN, BN 1271, exp. 1). 
El conocimiento de las lenguas indígenas se daba por varios medios: algunos las aprendían desde niños de forma práctica en sus pueblos de origen; otros, quizá los menos, hacían lo propio en las cátedras de lengua de colegios o en la universidad, lo cual no los eximía de tener que practicarlo con indios nati$\operatorname{vos}^{7}$. Finalmente, un tercer sector de clérigos emprendía su aprendizaje una vez que terminaban sus cursos escolásticos, trasladándose a pueblos de indios de su elección, a veces aprovechando su nombramiento como ayudantes del cura del lugar. Incluso curas titulares no aprendían un idioma sino hasta que ya estaban en funciones ${ }^{8}$.

Ahora bien, ¿dónde aprendían los clérigos a predicar, a decir misa, a cantar o a administrar los sacramentos? Es claro que no en la universidad. El paso siguiente para los futuros sacerdotes, después de la academia, era iniciarse en las tareas propias de su ministerio. Para ello, luego de recibir alguna orden sacra, desde las menores, eran enviados a las parroquias como ayudantes de los curas para que aprendieran de una manera práctica el oficio, luego de lo cual el cura encargado debía extenderles una certificación aprobatoria ${ }^{9}$. De esa manera se intentaba cumplir con lo preceptuado en el tercer concilio mexicano. Marcos Reynel, luego de haberse ordenado de subdiácono y diácono en 1724 "pasó al curato de Yanhualica a ejercerlos, en donde predicó continuamente el santo evangelio y explicó la doctrina cristiana, ayudando a los oficios de semana santa y a todo lo que al diácono es perteneciente". ("Provisión")

7 Tal expresó el bachiller Juan Manuel de Cea en su relación para opositar a los curatos vacantes en 1749: "Es originario del pueblo de Ixmiquilpan, de donde le viene ser nativo en el idioma otomí" ("Relación"). El bachiller Manuel Agüero expresó que, una vez ordenado de presbítero: "[...] se impuso por arte en el idioma mexicano y cursó esta cátedra en el real y pontificio colegio seminario más de ocho meses, haciendo en dicho idioma varias pláticas [...] todo para instruirse mejor en dicho idioma para cuyo fin se retiró fuera de esta ciudad a un pueblo de indios" ("Provisión").

8 El bachiller Diego Antonio Rodríguez, una vez graduado de bachiller en filosofía, hacia 1730, expresó que: "Por el mes de agosto de dicho año se retiró al pueblo de Mixquiahuala a aprender el idioma otomí, que consiguió en término de tres años, a cuyo título fue admitido a órdenes". Fue el caso del bachiller José Espino Barros, quien expresó así tal formación: "Tiene cinco años y medio de cura de tierra caliente, donde aprendió el idioma mexicano [...]" ("Relación")

9 En la relación de Miguel de Araujo se expresaba que: “[...] cerca de tres años se mantuvo en uno de los curatos de este arzobispado, en cuya administración se portó con el celo y tesón que consta por la certificación [...]" ("Provisión"). 


\section{FRONTERAS}

Manuel Agüero recibió una formación intensiva en la sierra de Cuautzingo, en un curato con 15 pueblos, bajo la vigilancia del cura titular ${ }^{10}$. José Manuel de Lora y Escobar expresó que tan pronto se ordenó y celebró su primera misa, se fue al partido de Tizayucan, lugar donde administró durante tres años y medio ("Provisión"). En ese curato, Lora se ejercitó en el confesionario diariamente, así como en sermones morales y panegíricos y pláticas doctrinales en castellano y en mexicano. En premio a sus nuevas capacidades, el arzobispo lo nombró como cura coadjutor de Tetela de Volcán.

Así, es claro que los clérigos del arzobispado de México no recibían su formación e instrucción en un solo lugar, sino que primero se preparaban académicamente para después continuar con su formación propiamente sacerdotal y de una o más lenguas indígenas, fuera de las aulas. También va siendo claro que algunos clérigos no se graduaban en la universidad, aunque igual es cierto que en esos casos no se podía esperar un buen curato o cargo eclesiástico (Taylor 151-152; Aguirre, El mérito 279-392). Veamos qué nos dicen algunos números en ese sentido.

\section{Un acercamiento a la demanda de grados por el clero secular}

Acerquémonos a tres ejemplos sobre la distribución y el tipo de grados que presentaba la clerecía en la Nueva España del siglo XVIII. Podemos tomar como ejemplo la situación que al respecto presentan los clérigos recién ordenados en el arzobispado de México entre 1717 y 1727. En esa década, sólo del clero secular, se ordenaron 791 individuos en todas las órdenes. De ellos, 467 tenían el grado de bachiller, 14 el de doctor, 15 el de licenciado y 2 el de maestro de artes; es decir, 498 (63\%) contaban ya con algún grado, mayoritariamente el de bachiller. Este porcentaje es mínimo si tomamos en cuenta que varios de los clérigos que no declaran grado eran apenas estudiantes y muchos lo obtuvieron después. Considero que no es exagerado decir que el $80 \%$ del clero secular del arzobispado de México contaba con al menos el grado de bachiller (AGN, BN 1271, exp. 1).

En Oaxaca, hacia 1761, de los 30 curas más distinguidos, según su propio obispo, sólo uno no tenía grado universitario, cinco lo tenían de doctor o licenciado y el resto eran bachilleres, la mayoría en artes, con un promedio de edad de 45 años (AGI, M 2550).

10 En su relación, Agüero calificaba así su aprendizaje como ministro: “[...] se portó con tal aceptación de su cura, que a su satisfacción pasó a administrar por sí solo lo restante del tiempo hasta ahora la ayuda de la parroquia de Santa María Tlaolan [...]" ("Provisión"). 
Para Michoacán contamos con una interesante relación de curas y presbíteros de 1764, enviada por el obispo Pedro Anselmo Sánchez de Tagle al rey, en la cual daba cuenta de las ocupaciones, edades, cualidades o defectos, así como de sus grados. Los resultados no pueden ser más claros sobre el asunto que aquí nos ocupa. En el ámbito de los curas propietarios, de un total de 68 sólo 8 tenían algún grado mayor en teología o cánones; el resto eran bachilleres. En los curas interinos la situación era similar: dos con grado mayor, seis bachilleres y sólo uno sin grado. En el resto de los presbíteros las proporciones se extreman: 15 son licenciados o doctores $(3,7 \%)$, de 17 no se menciona grado $(4,2 \%)$ y 376 son bachilleres, la mayoría sólo en artes o en filosofía $(92,1 \%)$.

\section{A manera de conclusión: el clero y los grados universitarios en Nueva España}

Después del recorrido aquí presentado, estamos ya en condiciones de puntualizar el tipo de relaciones que se dio a lo largo de la era novohispana entre el crecimiento del clero y la demanda de grados universitarios. Si bien es cierto que la normativa eclesiástica y tridentina, así como la real, no exigían al común de los clérigos la posesión de un título universitario para su desempeño, también lo es que las circunstancias históricas en que se fundó la iglesia novohispana las hicieron depender desde la segunda mitad del siglo XVI de las cátedras de la Universidad y del colegio jesuita, para la formación académica de su clerecía. En consecuencia, el grado universitario se convirtió en una especie de constancia de los clérigos para demostrar ciertos conocimientos básicos a sus superiores.

Sin embargo, ese proceso del siglo XVI no explica el porqué a pesar de la eventual fundación de colegios para clérigos en el siglo XVII, éstos siguieron buscando los grados, especialmente el de bachiller en artes. Según lo expuesto aquí, es claro que los clérigos, sobre todo los de otros obispados más allá de México, recibían toda su formación en sus regiones de origen y en realidad no necesitaban los cursos de la universidad. Entonces, si a pesar de ello, siguieron viajando a la capital novohispana a graduarse, debe reflexionarse sobre el motivo o los motivos que tenían para hacerlo. Veamos.

En primer lugar, un grado universitario daba a quien lo poseía, clérigo o no, la "sanción pública de idoneidad", como fue definido en la época; es decir, que la persona tenía los conocimientos necesarios para ejercer una profesión. En segundo lugar, un clérigo letrado siempre tendría mejores oportunidades de 


\section{FRONTERAS}

empleo que aquel que no tuviera grado. Ello lo sabía muy bien el alto clero novohispano, donde casi todos los jerarcas eran doctores. En tercer lugar, los clérigos al servicio de los obispos destacaban generalmente por la posesión de varios grados, aun cuando no tuvieran mucha experiencia en la cura de almas. Los mismos prelados solían favorecer más a presbíteros con buenas trayectorias académicas que a los sufridos curas rurales.

También era bien visto en los sínodos para ordenar a nuevos clérigos que un joven tuviera por lo menos un grado de bachiller que garantizara un mínimo de conocimientos, con el cual por lo menos podía ordenarse en las primeras órdenes por suficiencia.

Finalmente, para aquellos clérigos sin mucho ánimo de integrarse a las tareas espirituales, el grado les podía abrir puertas fuera de las instituciones eclesiásticas. No era raro hallar a muchos bachilleres clérigos alejados de tareas espirituales para quienes el grado quizá fue más importante. De esa manera, el grado universitario se convirtió en el mérito ideal para la mayoría de los clérigos que buscaban un beneficio o cargo eclesiástico, por más que lo negara el claustro universitario de 1753. Si a alguien la Universidad de México debía agradecer la demanda de miles de grados a lo largo de la época colonial, era a la Iglesia y su clerecía.

\section{Bibliografía}

\section{Fuentes primarias}

Archivo General de la Nación, México (AGN).

México (M) 2547, 2550.

Alcaldes Mayores (AM) 3.

Bienes Nacionales (BN) 41, 199, 271, 603, 1271.

Universidad (U) 55.

Archivo General de Indias, Sevilla, España (AGI)

"Provisión de curatos del arzobispado de México" (1768). Archivo General de la Nación (AGN), México. Bienes Nacionales 603, exp. 5. 
"Relación de méritos del bachiller Bernardino Pablo López y Escobedo". Archivo General de la Nación (AGN), México. Bienes Nacionales 199, exp. 12.

"Informe reservado de la clerecía del arzobispado de México, por Manuel José Rubio y Salinas" (febrero de 1764). Archivo General de Indias (AGI), Sevilla. México 2547.

\section{Fuentes secundarias}

Aguirre Salvador, Rodolfo. "Grados y colegios en la Nueva España, 17041767”. Tzintzun. Revista de Estudios Históricos 36 (2002): 5052.

-. El mérito y la estrategia. Clérigos, juristas y médicos en Nueva España. México: Centro de Estudios Sobre la Universidad; Universidad Nacional Autónoma de México, 2003.

—. "El perfil de una élite académica en la Nueva España del siglo XVIII: los licenciados y doctores canonistas". Universitarios en la Nueva España. Colección de la Real Universidad de México. Estudios y textos XV. Coord. Armando Pavón Romero. México: Centro de Estudios Sobre la Universidad, 2003. 51-84.

—. "Formación y ordenación de clérigos ante la normativa conciliar. El caso del arzobispado de México, 1712-1748”. Los concilios provinciales en Nueva España. Reflexiones e influencias. Pilar Martínez López- Cano y Francisco J. Cervantes Bello, coords. México: Universidad Nacional Autónoma de México; Benemérita Universidad Autónoma de Puebla, 2005. 337-362.

Aguirre Salvador, Rodolfo, Leticia Pérez y Enrique González. I y II Concilios. Estudio introductorio, transcripción paleográfica y anexos. Concilios provinciales mexicanos. Época colonial por Pilar Martínez López-Cano, coord. CD-ROM. México: Instituto de Investigaciones Históricas; Universidad Nacional Autónoma de México, 2004.

Chávez Sánchez, Eduardo. Historia del seminario conciliar de México. t. 1. México: Porrúa, 1996. 


\section{FRONTERAS}

de la historia

Gonzalbo, Pilar. Historia de la educación en la época colonial. La educación de los criollos y la vida urbana. México: El Colegio de México, 1995.

González, Enrique. "Legislación y poderes públicos en la universidad colonial mexicana (1551-1668)". Tesis de doctorado. Universidad de Valencia, 1990.

Kagan, Richard L. Universidad y sociedad en la España moderna. Madrid: Tecnos, 1981.

León Alanís, Ricardo. El Colegio de San Nicolás de Valladolid. Una residencia de estudiantes. 1580-1712. Morelia: Universidad Michoacana de San Nicolás de Hidalgo; Instituto de Investigaciones Históricas, 2000.

Martínez López-Cano, Pilar, coord. Concilios provinciales mexicanos. Época colonial. CD-ROM. México: Instituto de Investigaciones Históricas; Universidad Nacional Autónoma de México, 2004.

Menegus, Margarita y Rodolfo Aguirre. Los indios, el sacerdocio y la universidad. Siglos XVI-XVIII. México: Centro de Estudios sobre la Universidad; Plaza y Valdés, 2006.

Ramírez, Clara I. y Armando Pavón. "La carrera universitaria en el siglo XVI. $\mathrm{El}$ acceso de los estudiantes a las cátedras". Los estudiantes. Trabajos de historia y sociología. Renate Marsiske. México: Centro de Estudios Sobre la Universidad; Universidad Nacional Autónoma de México, 1989. 56-100.

Taylor, William. Ministros de lo sagrado. t. 1. México: El Colegio de Michoacán; Secretaría de Gobernación; El Colegio de México, 1999.

Fecha de recepción: 15 de noviembre de 2007.

Fecha de aprobación: 15 de mayo de 2008. 